\section{ScienceDirect}

Materials Today: Proceedings XX (2017) XXX-XXX materialstoday:
PROCEEDINGS

www.materialstoday.com/proceedings

\title{
AEM2017 \\ Material aspects of underwater marine systems in Greece
}

\author{
Alexandros G. Oikonomou ${ }^{\mathrm{a}}$, George A. Aggidis ${ }^{\mathrm{b}, *}$ \\ ${ }^{a}$ PhD Candidate, MSc in Welding Engineering, Metallurgical Engineer, Lancaster University Renewable Energy Group and Fluid Machinery \\ Group, Department of Engineering, Lancaster University, Lancaster, Bailrigg, Lancashire, LA1 4YR, United Kingdom \\ ${ }^{b}$ Professor, Lancaster University Renewable Energy Group and Fluid Machinery Group, Department of Engineering, Lancaster University, \\ Lancaster Bailrigg, Lancashire, LA1 4YR, United Kingdom
}

\begin{abstract}
The material selection for the improvement of the quality of already existing underwater marine systems (including oil platforms) and for the construction of new and unfamiliar underwater sea-structures (including the submerged parts of Wave Energy Converters and Tidal Energy Converters) in many countries like Greece is an essential parameter from a technical, qualitative and economical point of view. The purpose of this review paper is to present a justified analysis of the proposed materials, explaining in more details the advantages of their properties and focusing on the applicable welding issues taking into consideration the previous existing experience from shipbuilding and submarine constructions.
\end{abstract}

(C) 2017 Elsevier Ltd. All rights reserved.

Selection and/or Peer-review under responsibility of AEM2017.

Keywords: Corrosion Resistance; Weldability, Marine Systems; Flux Cored Arc Welding; Submerged Arc Welding, HY 100 steels, Hydrogen Induced Cracking, Non Destructive Evaluation

\section{Introduction}

The selection of the most suitable material for the construction of various welded underwater marine systems in the Greek seas depends on the following important properties: (a) good mechanical properties (yield strength, tensile strength, hardness, toughness at low temperatures, ductility and weldability), (b) high corrosion resistance, (c) local environmental factors (e.g. sea salinity, velocity of sea water, temperature, depth of immersion) which affect the corrosion rate (d) high life durability and low degree of maintenance, (e) economic factors (cost of raw material, cost of maintenance, cost of installation and removal) [1].

\footnotetext{
* Corresponding author. Tel.: +0-044-152-459-3052.

E-mail address: a.oikonomou@ lancaster.ac.uk; g.aggidis@lancaster.ac.uk
} 
Although many different materials (e.g. titanium, aluminum alloys and bronze alloys) have been developed and used for marine applications around the world, steels are the most representative widely used materials in shipbuilding, submarine constructions and other relative fabrications because steels are approximately five times cheaper than aluminum [1,2]. In Greece steels are currently used in the previously mentioned constructions and consequently this pre-existing application can be the basis for the construction of unfamiliar underwater sea systems (like the submerged parts of Wave Energy Converters and Tidal Energy Converters). For instance, in the case of the installation of Wave Energy Converters in Greece, previous researchers have illustrated that the Wave Energy Converters can be installed in specific locations (the Ionian Sea and the straights between Crete-Kithira, CreteKasos, Kasos-Karpathos and Karpathos-Rhodes islands) where the seasonal and annual average of the wave energy potential is satisfactory [3].

\section{Important Material Properties Required for Underwater Marine Applications}

Low corrosion resistance is a one of the most important problems which causes qualitative deteriorations and rapid failures of the marine constructions and decreases the human safety [4]. On 10 April 1963 the nuclear submarine USS Thresher was sunk, all crew and shipyard personnel abroad were killed and the radioactive power unit was detected in the floor of the Atlantic Ocean due to the failure of a defective soldered joint in a seawater system [4]. The chemical or electrochemical reactions that occur between the steel and the surrounding seawater are influenced by the seawater temperature, salinity of the seawater, seawater velocity, seawater $\mathrm{pH}$, concentration of dissolved oxygen, marine growth and the bacterial presence, depth of immersion, season of initial immersion, the contact of the marine structure with other materials (e.g. stainless steel, copper, brass or magnetite) and the presence of organic materials (pollution) in seawater $[1,4]$.

An increase of the sea temperature for every $10^{\circ} \mathrm{C}$ will double the corrosion rate of the steel at the initial (electrochemical kinetics - controlled) phase of corrosion [4]. At the second phase of corrosion, when the process is controlled by diffusion, the solubility of oxygen in seawater is decreased and consequently the corrosion rate is doubled when a rise of $30^{\circ} \mathrm{C}$ is observed [4]. The relationship between the dissolved oxygen concentration and the corrosion rate is linear. The reduction of the sea salinity (Fig. 1) does not cause reduction in the corrosion rate because it was observed that some steels corroded at greater rates with decreased sea salinity [4]. An increase of the depth of immersion (from 1.5 to $50 \mathrm{~m}$ ) will increase the corrosion rate about 1.3 times whereas a higher increase of the depth of immersion (from 50 to $500 \mathrm{~m}$ ) will decrease the corrosion rate [4]. The steel is highly corroded again in water deeper than $500 \mathrm{~m}$ and the rate at $5000 \mathrm{~m}$ is 1.5 times the rate at $1.5 \mathrm{~m}$ [4]. The highest corrosion rate was seen at depth of 2000-5000 $\mathrm{m}$ [4]. The average annual corrosion rate for a steel specimen immersed in seawater in winter period was 1.3 - 1.4 times lower in comparison with the respective rate for a steel specimen immersed in summer period [4]. The contact of the marine structure with other materials increases the total corrosion rate because of the contribution of the galvanic corrosion [4]. The seawater pollution increases the corrosion rates of the steels [4].

The corrosion rate $(\mathrm{mm} / \mathrm{year})$ of the material is influenced by the previously described environment factors which predominate in the areas under examination. The Aegean Sea basin, which is situated between Greece and Turkey, has a maximum depth of $2568 \mathrm{~m}$, average sea salinity higher than $37 \mathrm{ppt}$, a surface area of $192,026 \mathrm{~km}^{2}$ and a volume of $7.4 \times 10^{4} \mathrm{~km}^{3}$, whereas the Ionian Sea basin, has a maximum depth higher than $5121 \mathrm{~m}$, average sea salinity higher than $37 \mathrm{ppt}$, a surface area of $173,493 \mathrm{~km}^{2}$ and a volume of $10.8 \times 10^{4} \mathrm{~km}^{3}[5,6]$.

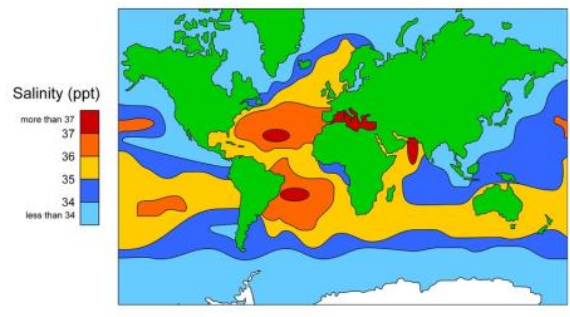

Fig 1. Global distribution of the average sea salinity [6] 
The high weldability, and consequently the good welding quality, is affected by the optimization of the values of various welding parameters (e.g. welding current, welding voltage, welding speed, wire feed speed, shielding gas composition, shielding gas flow rate, etc.). Welding Procedure Specification is a document describing in detail the joint design, the name of the applied welding process, the edge preparation and all the required welding parameters for specific application such that the repeatability by trained and certified welders and welding operators is ensured $[7,8]$

The welding current, which has a nonlinear relationship with the wire feed speed or melting rate for a specific electrode/wire diameter, composition and stick-out, influences the deposition rate, the degree of penetration and the shape of the weld bead [8,9]. By increasing the welding current, the weld becomes higher and narrower with a greater depth of penetration $[8,9]$. By decreasing the welding current, the penetration gets smaller, the deposition rate becomes lower and the weld bead becomes smaller [8]. Extremely high values of welding current can cause many welding defects such as the undercut (i.e. one common unimportant defect appeared in fillet welds and it is the groove melted in the parent metal next to the weld root or weld toe which is not filled by the filler metal), spherical or cylindrical porosity (i.e. bubbles or cavities which are produced from dissolved gas in the molten metal, appear during the welding execution and are trapped when the molten metal solidifies), burn - through and thermal cracking $[7,8,9]$. Extremely low values of welding current can cause many welding defects such as the incomplete fusion (i.e. one defect which occurs when the fusion of the filler metal to the parent metal is not completely observed), the overlap or cold lap (i.e. the welding defect where the deposition of the filler metal in fusion welds is visually larger than the weld interface at the toe of either a fillet or groove weld, as well as at the root of a groove weld) $[7,8,9]$.

The welding voltage or arc length is the electrical potential between the wire and the workpiece $[8,9]$. An extremely high welding voltage can cause excessive spatter, undercuts and non uniform weld beads. Low welding voltage causes inclusions and incomplete fusion $[8,9]$.

The welding speed is the rate at which the movement of the arc along the joint is executed [8]. By increasing the welding speed, the weld becomes narrower and the penetration smaller. By decreasing the welding speed, the deposition of the filler metal per unit length increases and the weld bead become larger. The appearance of undercuts, porosity, root imperfections, inadequate fusion and magnetic blow effect can be caused due to the extremely high value of the welding speed. Moreover, the appearance of the overlap, the excessive spatter and of a mushroom - shaped penetration which produces thermal cracking and slag inclusions (i.e. entrapped nonmetallic materials in the filler metal) can be caused by an excessively low welding speed [8,9].

The electrode/wire stick - out or electrode/wire extension is the distance between the end of the contact tube and the end of the electrode/wire [8]. A normal value of this factor is 10-15xdiameter of the electrode/wire [9]. Increasing the electrode/wire stick out, the electrical resistance of the electrode/wire is increased, but the welding current, the wire feed speed and the heat input are decreased while the deposition rate of the filler metal remains constant. The increase of the electrode/wire stick out reduces the penetration and as a consequence incomplete fusion can be visible $[8,9]$

The shielding gases are consumables directed by the torch to the arc and weld pool and are used for the protection of the molten metal from oxidation and contamination [8,9]. Shielding gases, used for the welding execution, can be grouped into inert gases (i.e. argon, helium), active gases (i.e. carbon dioxide) or a mixture of these gases [8]. Helium has 0.14 times higher density than air, while the density of argon is just over 1.4 times that of air [8]. The heavier the shielding gas is, the more effective it is for the protection of the welding arc. The suitability of argon for: (a) welding thin materials and materials with lower thermal conductivity, (b) providing reduced penetration, (c) providing cleaning action in aluminum and magnesium welding, (d) being cheap and offering two to three times lower flow rates than helium, (e) providing an easier establishment of the welding arc than helium makes its use as a shielding gas very frequent because less heat is produced with argon than with helium [8]. Helium has a higher thermal conductivity and a higher ionization potential than argon [8]. Carbon dioxide $\left(\mathrm{CO}_{2}\right)$ is the most widely used shielding gas for Flux Cored Arc Welding process because it is inexpensive and provides higher welding speed and greater joint penetration [8]. The heating of the $\mathrm{CO}_{2}$ to high temperature by the welding arc leads to the dissociation of $\mathrm{CO}_{2}$ such that carbon dioxide $(\mathrm{CO})$ and oxygen $(\mathrm{O})$ are produced [8]. Consequently a reduction in the filler metal content of elements (silicon, manganese and titanium) and an increase in carbon is observed [8]. The mixture commonly used during the execution of the gas shielded Flux Cored Arc Welding process is $75 \%$ Argon and $25 \% \mathrm{CO} 2$. Contamination or presence of humidity in the shielding gas can cause the appearance of spherical or cylindrical porosity [8]. 
The low or inadequate shielding gas flow rate causes the appearance of porosity and contamination of the molten metal whereas the extremely high flow rate causes turbulence [8].

\section{Important Materials for Underwater Marine Applications}

This chapter reviews and presents three different steels with low cost which can be used for the improvement of the quality of the already existed welded underwater marine systems and for the construction of new and unfamiliar underwater welded marine systems in Greece.

The physical, chemical and mechanical properties of the steels are affected by their alloying elements. Hardness, hardenability, yield strength and tensile strength are increased due to the carbon contents of the steel whereas weldability, toughness, ductility and elongation and reduction in area generally decrease with increasing carbon content. Silicon which is a basic deoxidizer used in steel production enhances the strength of ferrite without causing a severe loss of ductility. Manganese contents enhance the hardenability and the machinability of steel by forming manganese sulfides but decrease ductility and weldability to a smaller degree than carbon. Increasing phosphorous content increases hardness, yield strength and tensile strength of the steel but seriously lowers toughness and ductility. Some small additions of phosphorus will enhance the steel's corrosion resistance. Sulfur which exists in the form of sulfide inclusions is desirable for the only reason that the machinability of the steel is increased but it severely decreases weldability, toughness and ductility of the steel. Chromium additions in steels increase resistance to oxidation and corrosion and enhance hardenability, hardness and toughness. Nickel increases toughness and, when it is combined with chromium, it produces steels with improved hardenability and fatigue resistance. Molybdenum additions increase the hardenability of the steels [10].

Hydrogen induced cracking or cold cracking or delayed cracking or underbead cracking is the basic defect associated with the welding execution of the three steels which are presented below. During the welding execution hydrogen content is unrestrictedly introduced into the molten weld pool from the arc atmosphere and during cooling high amounts of hydrogen effuse from the solidified bead, while some others are entrapped into the heat affected zone of the parent metal. Hydrogen induced cracking is observed in the heat affected zone of the parent metal (i.e. the weld toe, the weld root or in an under bead position) or in the filler metal up to 48 hours, several weeks or months after the integration of the welding execution $[7,11]$.

Hydrogen cracks, which may be subsurface or may cause failure in the weld surface can have many variations in length from some microns to several millimeters. Hydrogen induced cracking is not easily identified because it is observed in a wide range of orientations. In butt welds heat affected zone hydrogen cracks are oriented perpendicularly to the weld, but in filler welds cracks are observed alongside the weld. In the case that hydrogen induced cracking is observed in the filler metal it can be transverse or parallel to the weld direction. Transverse cracks have perpendicular or just over a $45^{\circ}$ angle to the weld surface (chevron cracks) orientation [7,11].

The appearance of Hydrogen Induced Cracking is caused by the four following independent factors which must occur simultaneously: (1) Presence of diffusive hydrogen to a noticeable extent in the room air, in welding consumables and in the surface of the steels to be welded which comes from different sources. The source of hydrogen in the room air is moisture. The sources of hydrogen in welding consumables are the following: (a) Moisture from the shielding gas, from the flux which is used during the execution of the Submerged Arc Welding process or from the flux cored wires which are used during the execution of the Flux Cored Arc Welding process, (b) Oil, dirt and grease which are present in the surface of welding wires, (c) Rust on the surface of welding wires. The sources of hydrogen from the steels to be welded are: (a) Moisture in the surface from the material to be welded, (b) Fluids used for cleaning the surfaces of the material prior to the welding execution, (c) Oil, dirt, paint grease, rust, grease on the surface and nearby to the edge preparation. The higher the hydrogen level is, the lower is the resistance to Hydrogen Induced Cracking formation. (2) Presence of residual stresses on welds, which are usually concentrated at the root and toe of the weld and must not be ignored because stresses are essentially dependent on the size of the weldment, fit-up, external restraint and the yield strengths of the parent metal and filler metal. (3) A susceptible hardened (i.e. martensitic or bainitic) microstructure in the heat affected zone of the parent metal which depends in the cooling rate after the welding execution, the composition and the hardenability of the steel. During the welding execution and the subsequent rapid cooling (quenching) the temperature of the heat affected zone is higher than one of the adjacent parent metal and a hardened microstructure is caused. (4) Hydrogen Induced Cracking is likely to 
occur in steel plates in temperatures below $250^{\circ} \mathrm{C}$ because hydrogen cannot diffuse away and consequently the toughness of the steel is decreased [7,11]

The methods of the Non Destructive Testing which are executed for the detection of defects in steel weldments are the following:

Visual testing, which is very simple, quick and cheap method used for the inspection of the welds of the steels, can be executed with the aid of a flat or concave mirror, a hand magnifying glass, a small hand lens (magnification 2 $-4 \mathrm{x}$ ) and the boroscope or intrascope with built - in illumination. Visual testing is applied before the welding execution, during the welding execution and after the welding execution by illuminating the area under examination with light in the visible region. Visual testing is executed before the welding execution by the certified welding inspector in order to check that: (a) the quality and condition of the parent and filler metal is acceptable, (b) the condition of the welding equipment, (c) the shape and the dimensions of the edge preparation are these which are described in the Welding Procedure Specification, (d) the surfaces which are going to be welded are correctly fixed. Visual testing is executed after the welding execution by the certified welding inspector in order to check that: (a) every welding pass is cleaned before its coverage from the next pass, (b) there are no visible welding defects, (c) check that the arithmetic values of the welding parameters are exactly these which are described in the relative Welding Procedure Specification [7,12]

Dye or Fluorescent Penetrant methods are methods of Non Destructive Testing where a liquid is put on the surface of the steel weldment and after some time all the welding defects are revealed due to the presence of the liquid. [12]

Magnetic particle testing is an inexpensive and simple method of Non Destructive Testing which is used for the detection of open - to - surface and subsurface cracks in ferromagnetic materials (such as iron, nickel and cobalt alloys) in which the deposited filler metal is also ferromagnetic [7,12]. The principle of the Magnetic particle testing of non destructive evaluation is that the specimen is magnetized such that magnetic lines of force (magnetic flux) can be produced in the ferromagnetic material. In the case that the magnetic lines of force meet a discontinuity (e.g. crack) the production of secondary magnetic poles at the faces of the crack is observed. The appearance of the magnetic lines of force which are near the surface of the material is executed by the application of magnetic particles such as powder in the U.S.A. or liquid suspension (magnetic ink) in the United Kingdom. The main methods of magnetization are: (a) magnetic flow or magnetic yoke technique in which the specimen is a part of a magnetic circuit by effectively using it as the bridge of a permanent or electromagnet, (b) current flow in which an electric current is passed, broadly along the direction and through the zone where defects are to be expected (c) induced current flow which is not applied in non destructive evaluation of welds and it is only used for ring specimens (d) electromagnetic induction. During the execution of the magnetic particle testing a special preparation on the surface to be inspected is not required but the areas under examination must be dry and free from loose paint, rust, scale, dirt and thin layer of adhesive paint such that the applied liquid suspension is not contaminated. The advantages of the magnetic particle testing method are: (a) its simple equipment, (b) it is a cheap method, (c) its possibility to indicate open - to - surface and subsurface discontinuities, (d) the surface of the material to be tested is not necessary to be ground and polished, whereas the limitations of the magnetic particle testing method are: (a) its restricted application in non - ferromagnetic materials (e.g. austenitic stainless steel), (b) its restricted application if a thick layer of adhesive paint $(>50 \mu \mathrm{m})$ is present, (c) a high number of tests is required for components of complex shape, (d) the sensitivity of the flaw can vary especially in components of complex shape because of the non uniformity of the magnetic field of the required intensity [7, 12].

Ultrasonic Testing is based on the principle of the introduction of high frequency ultrasonic waves (in the range from $500 \mathrm{kHz}$ to $10 \mathrm{MHz}$ ) into the material under examination by manually moving a small probe (the transducer) over the surface of the steel adjustment to the weld and watching a display of the travel time and amplitude of the ultrasonic pulses on an oscilloscope screen $[12,13,14]$. A suitable acoustic coupling medium (water, oil, grease and glycerin) is used between the face of the probe and the surface of the steel such that the high frequency ultrasonic waves are transmitted from the probe into the steel with some attendant loss of energy (attenuation) and they are reflected back from any defect $[12,13]$. The same probe or another probe acts as the receiver (transceiver) of the pulse of reflected ultrasound. The detection and the analysis of the reflected ultrasound gives sufficient information about the presence, the location, the possible identification and the size estimation of weld defects $[12,13]$. The ultrasonic waves, which are not electromagnetic radiation introduced into the material under examination, have the same characteristics with the sound waves but their essential difference is that their frequency is much higher than the frequency detected by the human ear (i.e. greater than $20 \mathrm{kHz}$ ) $[12,13]$. The wave velocity, which is different in 
different materials, can be estimated from the relationship: wave velocity $(\mathrm{cm} / \mathrm{sec})=$ wavelength $(\mathrm{mm}) \mathrm{x}$ frequency $(\mathrm{MHz})$. The types of waves used for the ultrasonic flaw detection in steel welds are compressional (longitudinal) and shear (transverse) waves but in some cases surface waves (i.e. Rayleigh, Lamb and Love waves) can be used $[12,13]$. Before the execution of the ultrasonic inspection the selected surfaces of the steels to be used for the scanning procedures must be free from weld spatter, loose scale, paint, dirt, machining and grinding particles such that the probe (s) can freely move. The surface roughness must be better than $6 \mu \mathrm{m}$ RMS for avoiding disturbance of the shape of the ultrasonic beam which could give mistaken about the presence, the location, the possible identification and the size estimation of weld defects $[12,13]$.

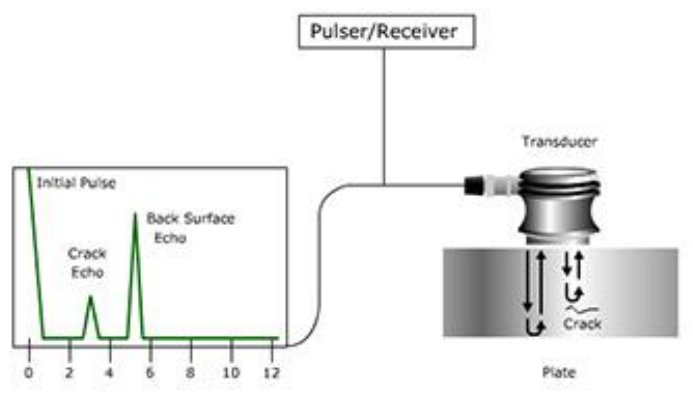

Fig. 2 The principle of ultrasonic flaw detection [14]

Radiographic Testing is a method of non destructive where the material under examination for flaw detection is positioned between the source of electromagnetic radiation ( $\mathrm{X}$ - rays and gamma - rays) and a sheet of photographic film (i.e. the radiograph) or photosensitive paper $[7,12,15]$. The $X$ - rays and gamma - rays have $2 \times 10^{-12}$ to $10^{-9} \mathrm{~m}$ and $10^{-13}$ to $2 \times 10^{-12} \mathrm{~m}$ wavelengths respectively [15]. The electromagnetic radiation is utilized because it: (a) cannot be reflected or refracted by lenses, prisms or mirrors, as it normally occurs with visible light, (b) has greater penetration onto the material under examination and shorter wavelength than the visible light, infrared, ultraviolet (UV) and radio waves, (c) is invisible by the human eye and (d) travels at the speed of light. Some amounts of the electromagnetic radiation will be absorbed as they pass through the material under examination, some radiation will be scattered and some radiation will be transmitted through the material onto the sheet of the photographic film $[7,12,15]$. Higher amounts of radiation will pass through a region of the material under examination where there is a flaw than through solid material and this essential difference in intensity will be recorded in the sheet of photographic film $[7,12,15]$. Afterwards the visual interpretation of the radiographs by positioning them on an illuminated film viewing screen will be executed. The $\mathrm{X}$ - rays are produced in a vacuum tube in the form of a glass envelope or metal - ceramic vessel which includes a source of electrons at one end (cathode) and a heavy metal target (anode). The anode consists of a block of copper which has satisfactory thermal conduction [7,12,15]. The electrons from the cathode are accelerated towards the anode such that the beam of the $\mathrm{X}$ - rays is generated $[7,12,15]$. Gamma - rays have high penetration in the material under examination and are generated during the decay of some radioactive materials (radium, uranium and others) and some artificial radioisotopes [12,15]. The artificial radioisotopes which are mostly used in Industry are the Cobalt - 60 for thick steel specimens between 50 $150 \mathrm{~mm}$ and the Iridium - 192 for thick steel specimens between $10-75 \mathrm{~mm}$ and the artificial radioisotopes which have a restricted usage in Industry are Cesium - 137, Cesium - 134, Ytterbium - 169, Thulium - 170 and Selinium -75 [15]. The usage of $X$ - rays and gamma - rays in RT has many advantages and disadvantages. $X$ - rays: a) have big, expensive and heavy in weight apparatus with many maintenance requirements, b) have an electrical power supply either from the mains or from the generator, c) are normally $60^{\circ}$ perpendicular to the longitudinal direction of the tube, d) are dangerous only during exposure whereas gamma - rays: a) have inexpensive apparatus, b) do not require power supply, c) are emitted in every direction, d) have continuous danger of radiation. When electromagnetic radiation is incident in the material then the amount of electromagnetic radiation transmitted to the radiograph is estimated by the relationship $\mathrm{I}=\mathrm{Ioe}^{-\mu t}$ where Io is the intensity of the incident beam, $\mathrm{I}$ is the intensity of the transmitted beam, $e$ is the base of the natural logarithm, $\mu$ is the linear absorption coefficient and $t$ is the thickness of the material $[12,15]$. The advantages of the radiographic testing are: (a) its application in different types of materials, (b) the detection of surface and subsurface defects, (c) the gamma - ray equipment is cheaper and more easily portable than the $\mathrm{X}$ - ray equipment and it is not depended on electrical and water supplies, (d) the film can 
be stored as a permanent record of the quality of the weldment whereas the disadvantages of the radiographic testing are: (a) the utilization of electromagnetic radiation which is dangerous and hazardous because it can damage or destroy the living cells, (b) its requirements of high cost equipment for thick ferrous materials (>150 mm), (c) very expensive $\mathrm{X}$ - ray machines, isotopes and their related licensing, (d) its difficulty to detect laminations in plate $[12,15]$.

\subsection{HY 100 steels}

HY 100 is an 100000 - psi high yield strength quenched and tempered fully killed and non-magnetizable steel with a good combination of strength and toughness which is used for submarine constructions and has many industrial applications in pressure vessels $[16,17]$. The basic advantages of the HY steel materials are their excellent resistance to underwater explosion shocks and their good weldability in heavy thicknesses with little preheat or no post weld heat treatment. The chemical analysis of the HY 100 steel is presented in table 1 [16]:

\begin{tabular}{|c|c|}
\hline Element (wt \%) & MIL-S-16216 \\
\hline Carbon & 0.20 Max. \\
\hline Silicon & $0.15-0.35$ \\
\hline Manganese & $0.10-0.40$ \\
\hline Phosphorus & 0.025 \\
\hline Sulphur & 0.025 \\
\hline Copper & 0.25 \\
\hline Chromium & 0.02 \\
\hline Nickel & $2.25-3.50$ \\
\hline Molybdenum & $0.20-0.60$ \\
\hline Titanium & 0.02 \\
\hline Vanadium & 0.03 \\
\hline
\end{tabular}

Taking into consideration the industrial experience it is observed that the HY 100 steels are welded with specific fusion welding processes such as the Shielded Metal Arc Welding, Submerged Arc Welding, Gas Metal Arc Welding, Flux Cored Arc Welding [16]. Flux Cored Arc Welding and Submerged Arc Welding are presented below because they are more advantageous welding processes compared with the others:

Flux Cored Arc Welding process is a semi - automatic or automatic arc welding process in which the heat required to melt and weld the material is produced by the establishment and maintenance of an electric arc between the tip of a continuously fed consumable filled with a flux and the work piece [8]. This process has the same equipment with the Gas Metal Arc Welding but the generally higher values of welding currents which can be used with cored filler wires require power sources with higher capacity [8]. Flux - cored welding wires provide high deposition rates and have higher resistance to draughts than metal arc electrodes. The fume produced from the usage of flux - cored welding wires is higher than the one produced from the usage of metal arc electrodes. The advantages of this process are: (a) resistance to cracking defects, (b) excellent smooth and uniform weld appearance, (c) high deposition rate which is four times greater than the deposition rate created by Shielded Metal Arc Welding, (d) ability to be used for welding of a wide range of thicknesses in many types of steels, (e) illustrating eliminated distortion compared with the Shielded Metal Arc Welding process, (f) high operator factor, (g) the cleaning required before of the welding execution is less than the one required in Gas Metal Arc Welding, whereas the limitations of the this process are: (a) restriction to welding ferrous metals and nickel base alloys, (b) the need for removing the slag covering the passes, (c) the fumes and smoke produced in Flux Cored Arc Welding are higher than those produced in Gas Metal Arc Welding and Submerged Arc Welding, (d) more maintenance of the equipment is required because of the complexity of the equipment [8]. 
Submerged Arc Welding process is a semi - automatic or automatic or mechanized arc welding process, in which the heat required to melt and weld the steel plates is generated by the initiation and maintenance of an electric arc between the tip of a continuously fed filler wire and the work piece. This process can be used in pipe welding, shipbuilding, in heavy structural steelwork and in general fabrications [8,9]. The Submerged Arc Welding process is schematically illustrated in figure 3 and the utilized welding current ranges between 350A and 2000A [8,9,18]. This process does not utilize a shielding gas but it utilizes a granulated mineral flux for the stability of the welding arc, for the control of the chemical and mechanical properties of the final weld deposit and for the protection of the welding zone from atmospheric contamination [8,9,18]. The different types of fluxes are fused, bonded (also known as agglomerated) and mechanically mixed [8,9]. The preparation of the fused fluxes includes melting and dry-mixing of the raw ingredients at high temperature in an electric furnace, such that a glass-like mass is generated. This mass is permitted to cool, and is afterwards broken up, screened to suitable grain sizes and packaged. The fused fluxes must have good chemical homogeneity and they must not be hygroscopic [8,9]. The composition of the fused flux is not affected because the fines can be easily removed. The preparation of the bonded fluxes includes powdering, drymixing and bonding or sintering the raw material with a binder (potassium silicate, sodium silicate or a mix ture of these two) in a rotary kiln at a temperature of $600-900^{\circ} \mathrm{C}$ [8,9]. Then the material is broken up, screened to suitable grain sizes and packaged. The bonded fluxes are unfortunately hygroscopic and they have relatively low grain size. The preparation of the mechanically mixed fluxes includes mixing of two or more fused or bonded fluxes in any ratio such that the desirable results are accomplished. The advantages of the this process are its high weld quality, its high melting and deposition rates, its deep penetration and its automatic operation, whereas the limitations of the this process are the difficulty of welding in any position, the invisible arc radiation, the relatively high equipment cost and its suitability for materials with thickness higher than $6 \mathrm{~mm}[8,9,18]$.

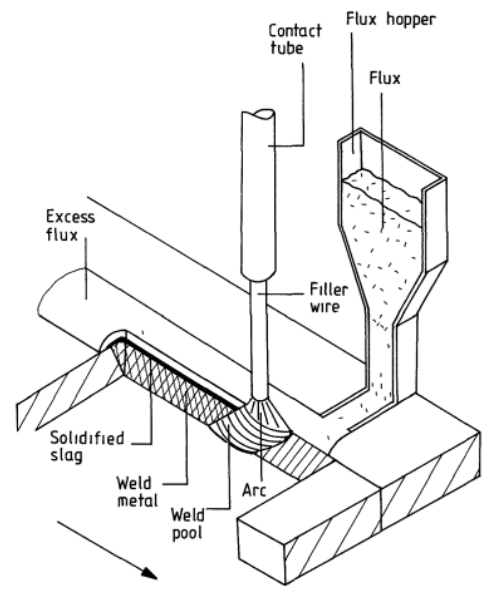

Fig. 3. Schematic View of Submerged Arc Welding Process [18]

\subsection{X6CrNiMo17-12-2 (316Ti) stainless steel}

The X6CrNiMo17-12-2 (316Ti) austenitic stainless steels are steels with titanium stabilization, the nominal chromium content higher than 16 percent and an excellent notch toughness at cryogenic temperatures [19]. The principal advantages of 316Ti steels are their higher corrosion and oxidation resistance than the standard grades of 316 , their better ductility and toughness than carbon and alloy steels and their good maintenance at elevated temperatures for a longer period without the presence of precipitation taking place $[19,20]$. The immersion of the 316Ti steel sample in boiling $42 \%$ magnesium chloride $\left(\mathrm{MgCl}_{2}\right)$ solution can indicate the likelihood of appearance of transgranular or intergranular Stress Corrosion Cracking in the 316Ti steel [19]. SCC is caused by the simultaneous subjection of the 316Ti steel in a tensile stress and its exposure in one specific corrosive medium (caustic or chloride solutions) [1]. The resistance of the 316Ti to the pitting corrosion is significantly affected by the surface treatment [21]. The chemical analysis of this steel is presented in table 2 [21]: 
Table 2.Chemical Compositions of X6CrNiMo17-12-2 parent metal [21].

\begin{tabular}{ll}
\hline Element & (wt \%) \\
\hline Carbon & 0.04 \\
Silicium & 0.43 \\
Manganese & 1.69 \\
Phosphor & 0.026 \\
Sulphur & 0.002 \\
Nitrogen & 0.012 \\
Chromium & 16.5 \\
Nickel & 10.6 \\
Molybdenum & 2.12 \\
Titanium & 0.41 \\
Vanadium & 0.003 \\
\hline
\end{tabular}

\subsection{S355J2N steel}

S355J2N is a hot rolled normalized structural steel with a minimum yield strength of $355 \mathrm{~N} / \mathrm{mm}^{2}$ which has many common applications due to its excellent mechanical properties. The chemical analysis of this steel is presented in table 3 [22]:

Table 3.Chemical Compositions of S355J2+N parent metal [22].

\begin{tabular}{lll}
\hline Element (wt \%) & $\begin{array}{l}\text { Material thickness } \\
(6 \mathrm{~mm})\end{array}$ & $\begin{array}{l}\text { Material thickness } \\
(14 \mathrm{~mm})\end{array}$ \\
\hline Carbon & 0.17 & 0.15 \\
Silicium & 0.02 & 0.31 \\
Manganese & 1.59 & 1.41 \\
Phosphor & 0.011 & 0.014 \\
Sulphur & 0.011 & 0.014 \\
Nitrogen & 0.004 & 0.005 \\
Aluminum & 0.028 & 0.037 \\
Copper & 0.03 & 0.04 \\
Chromium & 0.02 & 0.06 \\
Nickel & 0.03 & 0.02 \\
Molybdenum & 0.001 & 0.005 \\
Niobium & 0.001 & 0.003 \\
Titanium & 0.001 & 0.003 \\
Vanadium & 0.003 & 0.004 \\
\hline
\end{tabular}

\section{Conclusions}

This paper has reviewed different types of steels which can be used for the construction of the Underwater Marine Systems in Greece. It is obvious that the previous research in the field of these steels is restricted probably due to the 
fact that some of them are used in specific applications (e.g. submarine constructions) where there was not the relative accessibility by previous researchers. The three steels under examination have many advantages (low carbon content which provides good weldability) and disadvantages (all welded steel types are susceptible to serious defects such as Stress Corrosion Cracking and Hydrogen Induced Cracking). For instance, although HY 100 steel has an excellent resistance to underwater explosion shocks due to its high yield strength and a satisfactory corrosion resistance due to the presence of nickel and chromium alloys it is very sensitive to hydrogen induced cracking during the welding execution. Furthermore in the case of 316Ti stainless steel the high amounts of chromium and nickel provide an excellent corrosion resistance. Currently the two authors of this paper have started their experimental and numerical welding investigations for the determination of the material with the best behavior and cost analysis and the outputs of this research will be published in future papers.

\section{Acknowledgements}

Many thanks to Mr. Alexandros John Oikonomou (Industry Technical Engineer, grandfather of the PhD Candidate Mr. Alexandros George Oikonomou) for his support and technical guidance and advise.

\section{References}

[1] B. Le Mehaute, Daniel M. Hanes, Ocean Engineering Science, Volume 9, John Wiley \& Sons, USA, 1990

[2] N. A. McPherson, Materials selection for current and future UK naval requirements, Ironmaking and Steelmaking, volume 38, no 3, 2011, pp. $161-167$

[3] T. Soukissian, N. Gizari, M. Chatzinaki, Wave potential of the Greek seas, WIT Transactions on Ecology and the Environment, vol. 143, 2011, pp. $203-213$

[4] M. Panayotova, Y. Garbatov \& C. Guedes Soares, Corrosion of Steels in Marine Environment, Monitoring and Standards, Safety and Reliability of Industrial Products, Systems and Structures, Taylor \& Francis Group, 2008, pp. 369-412.

[5] D. Genea, V. Amortila, E. Mereuta, E. Rusu, A Joint Evaluation of the Wind and Wave Energy Resources Close to the Greek Islands, Sustainability, Basel, 2017

[6] The figure is available at https://www.sciencelearn.org.nz/resources/686-ocean-salinity (assesses 10th September 2017)

[7] American Welding Society, Welding Inspection Handbook, third ed., Miami, USA, 1987

[8] American Welding Society, Welding Handbook, Volume 2, eighth ed., Miami, USA, 1991

[9] K. Weman, Welding processes handbook, Woodhead Publishing Limited, first ed., Cambridge, England, 2003

[10] A. C. Reardon, Metallurgy for the Non - Metallurgist, second ed., ASM International, Ohio, 2011

[11] N. Bailey, F. R. Coe, T. G. Gooch, P H M Hart, N Jenkins, P J Pargeter, Welding steels without Hygrogen Cracking, second ed., Abington Publishing, Cambridge, England, 1973

[12] R. Halmsam, Introduction to the Non-Destructive Testing of Welded Joints, second ed., Abington Publishing, Cambridge, England, 1996.

[13] The International Institute of Welding, Handbook of the Ultrasonic Examination of Welds, Abington Publishing, Cambridge, England, 1982

[14] The figure 2 is available at https://www.linkedin.com/pulse/ndt-ultrasonic-testing-salman-cader (assessed 10th September 2017)

[15]Handbook of Radiographic Apparatus and Techniques, The International Institute of Welding

[16] R. W. Flax, R. E. Keith and M.D. Randall, Welding the HY Steels, American Society for Testing and Materials, New York, 1971

[17] Ulrich Gabler, Submarine Design, Bernand \& Graefe Verlag, Bonn, Germany, 2000

[18] John Norrich, Advanced welding processes, second ed., Woodhead Publishing Limited, Cambridge, England, 2006

[19] American Welding Society, Welding Handbook, Volume 4, forth ed., Miami, USA, 1998

[20] J. Brnic , G. Turkalj, M. Canadija, D. Lanc, AISI 316Ti (1.4571) steel-Mechanical, creep and fracture properties versus temperature, Journal of Constructional Steel Research, Elsevier, 2011, pp. 1948-1952

[21] P. Fajnor, Tatiana Liptáková, V. Konstantová, Influence of AISI 316Ti stainless steel surface treatment on pitting corrosion in various solutions, Materials Engineering, Vol. 17, No. 3, 2010

[22]R. M. Plum, Fatigue crack detection on structural steel members by using ultrasound excited thermography, KIT Scientific Publishing, 2015 